International Journal of Engineering \& Technology, $7(2.5)(2018) 96-99$
International Journal of Engineering \& Technology
SPC
Website: www.sciencepubco.com/index.php/IJET
Research Paper

\title{
The Development of Curriculum School Model Based on the Internet of Things
}

\author{
Subagyo $^{1}$, Rasdi Eko Siswoyo ${ }^{1}$, Soesanto $^{1}$, Maman Rachman $^{1}$, Heri Nurdiyanto ${ }^{2 *}$ \\ ${ }^{1}$ Education Technology, Universitas Negeri Semarang, Jawa Tengah, Indonesia \\ ${ }^{2}$ Tecnology Vocational Education, Universitas Negeri Yogyakarta, Yogyakarta, Indonesia \\ Email: herinurdiyanto@gmail.com
}

\begin{abstract}
The background of this study is based on field conditions that Tamansiswa schools established since Indonesia have not been independent until now there has been no progress, even from schools that ever exist today many are closed due to lack of students. This research is classified in research and development, where researchers interpret the mindset and behavior of research subjects in carrying out the work. As the subject of the investigation is the principal in carrying out the work so far. The research was conducted at Vocational High School. The purpose of the study to describe the implementation of Vocational Middle School curriculum internet of things during this time, then, developed based on the internet of things theory and principles into the final model. Data collection using interviews, observation, and documentation. Data analysis is based on the qualitative descriptive study. The results showed that in the middle school Vocational Education did not implement the principles of the internet of things consisting of planning, implementation, and evaluation as a whole. The vision of the mission has not yet described the achievement of the targets, and the curriculum internet of things has not followed the accomplishments of the goals made before and is spontaneous, the evaluation of the implementation is not followed up and finished without any documents that can be used to reflect something done. This study concludes that the planning, implementation, and evaluation of curriculum internet of things industry 4.0 has not been optimal. The results of this study can be used as a reference for the implementation of curriculum based on the principles of the appropriate internet of things, a clear plan, and implemented realistically, and the existence of reflection and evaluation.
\end{abstract}

Keywords: Internet of things, curriculum, development.

\section{Introduction}

The existence of Tamansiswa School is almost a century, but its progress does not come. In the daily life of the school environment based on the principles of simplicity. It thus seems to have been inconsistent with the pattern of life of some people who are increasingly materialist, seeing things from the physical elements, especially the facilities and infrastructure saw and felt[1]. Tamansiswa School which was established on July 3, 1922, its existence is very apprehensive. As time passes, many new schools are organized and advanced, but Tamansiswa schools do not go through any changes even one by one of the ever closed due to lack of learners [2]. According to that of three hundred schools owned by Tamansiswa College experiencing mature because of lack of funds and only 30 percent live still worth operating. The principle of life "says simple and the like precisely weakens curriculum internet of things and makes no challenge, less discipline, and walk as it is. Schools in an era internet of things perspective are ideals that will be achieved through various things that need to be developed[3], [4]. Tamansiswa school curriculum internet of things has been using a particular culture approach, especially Java. This means that in teaching activities such as teacher teaching patterns, school discipline, existing facilities are very tolerant based on humanistic and straightforward ethics and values[5]-[7].
The principal in carrying out his functions always adheres to the prevailing value system, self-awareness, ingenuity or the will to innovate, and courage drawn under rules, rules, organizational ethics, school vision and mission and mutually agreed agreements. If these values of progress can be implemented into the school life, it does not rule out the purpose of the school will be realized [8]. Internet of things is a tool or a way used by people in the form of money, equipment, materials, and methods to achieve goals [9], [10]. It means internet of things is the whole process of activities by utilizing existing resources within the organization to make goals through planning, organizing, mobilization, and control [11]. Education internet of things is a process of developing a group of people to achieve goals through planning, organization, implementation, and supervision to realize the vision into action. About that, every school activity should be planned realistically [12]. What the internet of things function in the school perspective is in many ways between planning and organizational stages almost indistinguishable whether it is the planning stage or the organizing stage so that the plan and regulatory stages are usually simplified as a planning stage [13]. Based on the steps of the internet of things education consists of the level of strategy, implementation, on phase, and stage of supervision or evaluation. Review of curriculum internet of things of vocational schools to develop attitudes, knowledge, and skills and build learners' selfconfidence[14]-[16]. The result of the learning experience is the result of learning that describes the quality stated in the competen- 
cy standard of the graduates [17], [18]. Understanding competence according to Debling in John Burke competence pertains to the ability to perform the activities within a function or an occupational area to the levels of performance expected in employment." Power is a skill done to achieve specific standards under certain conditions [19]. Competency is a performance skill to particular rules under particular circumstances. The capability is closely related to the ability to perform work in the work area with the expected performance level. The talent is a combination of knowledge, skills, and attitudes that are reflected in the habits of thinking and acting. The forms of competence are grouped into two namely work competency and learning competency. Work competency is a set of original actions, full of responsibilities held as a condition to be deemed capable by the community in carrying out individual work, and competence expressed in the form of professional certification. Learning competency is a set of knowledge, skills, and attitudes to meet according to the criteria or objectives of learning, mastery of science and skills optimally. This means that in doing a job, someone does not doubt or doubt others who hire [20]. Principal leadership is the application of the theory and principles of the internet of things in the field of education in managing the school. In the control of the school curriculum according to Bush \& Coleman in, there are at least four main areas of concern for the implementation of internet of things the curriculum consists of; (a) development of learning materials, organizing students, timing of learning, and stimulating curriculum development; (b) supervise education; (c) monitor the progress of knowledge, and (d) condition a conducive learning climate [21]. According to Topping, an active leader must be skilled in the three components of development consisting of coaching, teaching, and mentoring. Robbins in Brundrett explains that the development of critical leadership knowledge focuses on the humanistic and instrumental aspects. As leaders need to emphasize the results and development performance of subordinates. As teachers need concentration help them to learn and apply new knowledge or skills acquired. As a mentor, it is necessary to focus on long-term career development and personal development [22]. The tendency that often occurs due to the education policy according to Dimmock is the creation of a similar leadership context in all schools in the form of institutions; (a) school-based internet of things, (b) the results are curriculum oriented, (c) competition in market forces, (d) the need for interschool communities, and (e) focus on quality standards and institutional accountability. The leadership of the principal who can turn into a conducive school managing the school into an existing school, and maintain the school into a school-oriented success. School internet of things into a functioning school can be done in the following way [23]. (a) To develop work ethics for staff and employees, (b) to keep school internet of things well managed; (c) to motivate teachers to have high expectations in school advancement; (d) develop teachers into models and play a decisive role; e) giving positive feedback and role to learners; (f) creating healthful working conditions for teachers, employees and learners; ( $\mathrm{g}$ ) providing the learners responsibility to develop themselves; (h) working between teachers and participants educate to share duty. Allman-oriented schools of success need specific strategies to build in a way; (b) emphasize the quality of learning, (c) have clear goals and expectations that enhance success both in teachers and learners, (d) develop a conducive school climate, (e) carry out ongoing monitoring and evaluation as part of growing the school culture, (f) managing the development of school resources, (g) involving parent support in school internet of things (h) engaging the community in school development.

\section{Methodology}

The object of the research and development of curriculum internet of things consists of Vocational High School of Tamansiswa Karanganyar as a school representing sub-district, Vocational School of Tamansiswa Purworejo as representative school, and Vocation- al School of Tamansiswa Yogyakarta as a school serving the province. The subjects consisted of 3 principals and three teacher representatives respectively. This research includes the type of research and development. Research activities were conducted to obtain data on curriculum internet of things of principals in the leads ranging from planning events, carrying out operations, and do supervision (evaluation). Once data is collected then data reduction is made by removing unnecessary data to create the actual design. The next step of the development step begins with making the conceptual model design later in the expert judgment expert generated the hypothetical model. This theoretical model is developed again based on theories that support more than in the judgment experiment through Forum Group Discussion (FGD) input to improve the conceptual design and produce the final model or final model

\section{Result and Discussion}

Based on the data obtained from field research results then made the actual design, of, curriculum internet of things model as below:

\section{A. Planning}

Vocational schools to go forward cooperation is needed with various parties, especially the business and industry that will become the consumer. The form of cooperation can be in the form of the activities of the teaching factory system, the internet of things of industrial work practices, the internet of things of the on-the-job training program, the industrial visits, the organization of the industrial class, or by organizing coaching by the users related to the employment. Implementation of teaching factory teaching model refers to competency-based learning and production-based learning. The real form of teaching system teaching system in the form of the provision of products in the form of production goods or services based on competence as the objectives to be achieved within the unit of production and services. The main task of the foundation to the school is to convey the important thoughts and signs that the foundation aims, to accelerate the work of the target institution, and to conduct monitoring and supervision. Monitoring and supervision activities undertaken have control objectives in case of irregularities and how to address them. In the supervision process there are five steps that need to be done; (a) the stipulation of implementation standards; (b) determining the size of the implementation of activities; (c) measurement of the implementation of activities; (d) comparison of the implementation of the the activities by standards and analysis of irregularities; and (e) taking corrective action when necessary. Monitoring and supervision actions within the Tasmania school environment, referring to the Ki Hajar Dewantara Leadership Trilogy in aspects of "Ing Ngarsa Sung Tulada, Ing Madya Mangun Karsa, and Tut Wuri Handayani." The principal should be well aware of the subject matter that becomes his main job. The principal task of the principal in school academic development consists of educational issues and teaching problems. The problem of education is how the principal can shape the character of schoolchildren to have a good personality, discipline, and resilience. Then there are at least six principal tasks in the school principal including (a) improving the quality of learning and establishing the learning program and formulating recommended learning methods; (b) supervising and evaluating the learning; (c) making the learning time allocation planning; ) coordinate curriculum development and implementation, (e) implement learning processes, develop, improve the quality and quantity of learning materials, and (f) monitor the progress of learning. About school progress, a principal has two main functions: (a) managing schools to be effective schools (school effective), (b) managing schools into successful schools. Manage schools into effective schools (school effective) in the form of work as follows. (a) developing a high work ethic for school staff and employees, (b) 
keeping school internet of things professionally managed, (c) motivating teachers to have high expectations in advancing schools, (d) developing teachers who teach as model and play a positive role, (e) provide positive feedback and role to learners, (f) create good working conditions for teachers, employees, and learners, (g) give large responsibility to learners to develop themselves, and (h) make sure that teachers and learners share tasks. Competence is a person's ability to behave, using knowledge and skills in the environment in which the person interacts. The curriculum is designed to provide the widest learning experience for learners to develop attitudes, knowledge, and skills to build their abilities. Competency-based curriculum internet of things is a variety of ways and or arrangements that are prepared to improve the quality of the learning process so that the competencies achieved are increased. In an effective organization, there should be steps of direction and motivation to members to always improve the quality of their performance. Monitoring measures are conducted in an integrated and sustainable manner with short, medium and long-term objectives of the stated objectives. In elaborating internet of things functions, it is necessary to define clear objectives and the determination of strategies, policies, work programs, procedures, methods, systems, budgets and standards in achieving objectives. In planning, decision-makers should be involved. The existence of proper planning will facilitate the principal to run the curriculum internet of things by looking at the changes that are happening in society. School Tool Work Program1) Needs Analysis Needs analysis is used to overcome the oversight of the internet of things in providing the means of learning both regarding numbers, variants, and quality. Identification of the essential learning infrastructure needs is essential to meet the demands of the community regarding the quality of resources required. Development of educational standards that include content standards, process standards, graduate competency standards, educator standards and education personnel, equipment and infrastructure standards, internet of things standards, financing standards, and assessment standards. Education facilities and infrastructure is one important element to produce quality graduates. 2) Goal SettingTo all activities carried out can be achieved based on a predetermined plan, it is necessary to set goals. Determination of objectives in written form can be used as school reference in carrying out activities and made realistic, measurable based on school riel condition in the time already taken into account. This goal allows the principal to perform its functions based on work plans that have been made and used as benchmarks of success. 3) Determination of Work ProgramThe school work program contains a description of the implementation of the school, ranging from planning, implementation, supervision, even to the making of reports. All parties within the organizational structure of the school need to have uniform steps, unity of language, and balance in carrying out their respective duties and responsibilities. The form of the work program that needs to be established is in the form of determining school curriculum, manpower internet of things , facilities and infrastructure, financing, student affairs, school and community relations, counseling guidance, library, planetarium, administration.

\section{B. Implementation}

The development of networking networks with external parties is beneficial for improving the quality of learning. In general, networks are tied together based on common vision, ideas, friends, descendants or others. Forms of school cooperation with external parties are used as a means of exchange information, request equipment, apprenticeship programs, distribution of graduates, and other needs. The essence of networking with external parties is to keep the school alive and become a part of people's lives. Cooperation networks are developed specifically in the form of values that need to be strengthened based on future ideas or ideas and vision. The existence of guidance on the achievement of competence can be used as a reference in organizing the learning process. Guidance on achieving that competence as a tool or equip- ment, while learning is the process or how to make the person succeed. Based on that with the guidance of the achievement of competence tools can be used by teachers to implement the learning process that allows learners to obtain or achieve maximum competence. The competency achievement toolkit is a medium used as a guide or instruction in a learning process and which parts may need to be developed. Organizational culture is built as a strategic step to strengthen the school so that not only focus on achievement of academic achievement alone. Curriculum internet of things is built to meet the demands of good governance, which meets the principles of democratization, transparency, accountability, and fairness. The leadership of democratic principals means leadership that can accommodate and pays attention to the aspirations of school residents; transparency means there is openness in leadership, accountable means accountable, fair and responsive to the development of the situation. The form of a school strengthening strategy is something that can support the success of school internet of things activities. School strengthening strategies can be physical or non-physical. School facilities and infrastructure in physical form, e.g., with the addition of equipment. The school facilities and infrastructure in a non-physical form such as applied internet of things style such as eliminating the barriers to superior relations with subordinates but still within the boundaries of mutual respect and fairness. Local wisdom developed should be based on the noble nature and local culture that is not contrary to the religious values that exist. There are several values of characters that can be used as a reference in teaching leadership patterns that can refine the mind which is the pattern of attitudes and daily behavior in Tamansiswa environment is the Ki Hajar Dewantara Trilogy. In general, the vocational school develops the potential of learners to have an independent, disciplined, and professional life in their field. The hope of the community that vocational schools can overcome various social problems that occur and equip them to enter the workforce. With the rise of spirit, the potentials that exist in a person will develop and wake up. Expectations from the business and industrial world environments so that vocational schools can provide prospective workers who have the appropriate job competencies required. Vocational schools can provide competency to prospective workers so that they do not need to train starting from the most basic level and hope can work immediately. Comprehensive assessments that need to be done in schools as a supervision and correction step consist of; a. the leadership of the principal, b. performance of the foundation, c. performance of teachers, $d$. learners and graduates, e. reporting activities, and f. an impact assessment as follows. Principal as a leader able to move the system of the organization include; (b) to organize a school institution in order to create a working together proportionally; (c) carry out school activities or activities so that they are in accordance with the intended targets; and (d) implement controls or institutional performance evaluation. The principal in performing its functions based on five aspects consisting of (a) able to cultivate developing issues and global culture, (b) have connectivity to various circles, (c) have the ability to deliver the message, (d) the preparation and readiness lead. An effective leader is a leader who can organize the organization structures and have a good friendship relationship. An effective leader is a leader who can handle both organizational and human aspects at once in his organization. The role of headmaster when in front or as a leader has a strong idealism and can explain the ideas of all parties and able to determine the direction and purpose of the organization he leads. While in the middle can provide motivation and encouragement and ability to grow the spirit to the citizens who led. When behind can direct, supervise and observe the implementation of work, and guide teachers, employees, and learners. Principals play a role as motivators in moving activities into and out and implemented democratically, participatory, transparent and accountable. The principal in developing curriculum internet of things should apply three social capital of capital related to the progress of the school consisting of bonding social capital (social capital bond) that is to establish social relationships with members within the school organization environment, bridging social 
capital (bridging social capital) is to establish a relationship with schools or organizations outside the school that are useful, and linking social capital is to establish links with the stakeholders and stakeholders such as government or local education office. The principal should be able to give everyone the opportunity to develop their profession to ensure that the products produced are acceptable to the public. b. Foundation Performance The foundation as policy maker should be able to carry out its duties and authority through interaction and cooperation with each other. Based on that every stage of policy implementation is always done evaluation action to avoid the lack of command and if there are deficiencies that may inhibit the process, need to be improved so that the achievement of the goal can be implemented effectively and efficiently. Then in fostering schools should be done using a participatory model. The participatory model is a combination of top-down and bottom-up models. c. The current World Teacher Performance has globalized the science of one intercorrelation and complementing it with others. Therefore, a teacher's perspective must also change unlimited within the local scope of regionalism but should be more than that, so it is not excessive if a teacher should understand the learning system developed through information technology to have a wider insight. d. Students and Graduates In the learning process learners are required to receive information that builds the mind (cognitive), build skills (psychomotor), and build a character (effective). Education is an attempt to advance the development of manners consisting of inner strength, power of thought and physical. It is intended that education can promote the perfect life and harmonize with the life of the community. Character or character is around soul then united into the motion of thoughts, feelings and desires that generate power or power. The word "mind" means mind or feeling. So character is human nature, starting from the delusion then turn into energy. e. Activity Reporting In every school activity there should be a note that can be seen that the work has been done. The benefits of a record can be used such as; (a) as material to report that work has been done, (b) as a guideline for subsequent activities, (c) as a correction if work is impeded later to be repaired, and (d) made a document when examined or as an evaluation and accreditation material. f. Impact Assessment An impact assessment of all activities is a supervisory step to improve the system already in operation. Impact assessment can provide clarification, guidance, coaching, and correct errors. Impact assessment is a systematic effort to conduct systematic observations. Supervision is the key to the success of the entire internet of things process that needs to be seen in a comprehensive, integrated, and not limited to formal matters. Implementation is the realization of planning into action to achieve goals effectively and efficiently.

\section{Conclusion}

The conclusion of the result of research and development of curriculum internet of things in Vocational High School Tamansiswa this that to produce graduates who are competency-based principals need to look again at the principles of school curriculum internet of things. At the planning stage of the school needs a realistic, realistic vision, a mission that can be implemented based on clear steps to meet the demands of quality. At the implementation stage of the school, it is conducting competency-based curriculum internet of things by developing cooperation network, achievement guidance, strengthening strategy, local wisdom values, community demands, and demands of Business World / Industrial World. At the evaluation stage, there needs to be a comprehensive assessment of curriculum internet of things implementation consisting of principal leadership, foundation performance, teacher performance, students and graduates, activity reporting, and impact assessment.

\section{References}

[1] National Center for Education Statistics, "Statistical Analysis
Report: Public Secondary School Teacher Survey on Vocational Education," 1994.

[2] R. L. Gibson and M. Mitchell, Introduction to Counseling and Guidance. Englewood Cliffs: Merril, 1995.

[3] M. R. Dal Poz, N. Gupta, E. Quain, and A. L. B. Soucat, "Handbook on Monitoring and Evaluation of Human Resources for Health: with special applications for low- and middle-income countries," p. 178, 2009.

[4] T. Listyorini and R. Rahim, "A prototype fire detection implemented using the Internet of Things and fuzzy logic," World Trans. Eng. Technol. Educ., vol. 16, no. 1, pp. 42-46, 2018.

[5] M. I. Mukhtar and J. Ahmad, "Assessment for Learning: Practice in TVET," Procedia - Soc. Behav. Sci., vol. 204, no. November 2014 pp. 119-126, 2015.

[6] A. S. Ahmar et al., "Lecturers ' Understanding on Indexing Databases of SINTA, DOAJ , Google Scholar, SCOPUS , and Web of Science: A Study of Indonesians," J. Phys. Conf. Ser., vol. 954, no. 1, p. 012026, 2018.

[7] K. Adiyarta, D. Napitupulu, R. Rahim, D. Abdullah, and M. Setiawan, "Analysis of e-learning implementation readiness based on integrated elr model," J. Phys. Conf. Ser., vol. 1007, no. 1, p. 012041, Apr. 2018.

[8] F. P. Deane, C. Gonsalvez, R. Blackman, D. Saffioti, and R. Andresen, "Issues in the development of e-supervision in professional psychology: A review. [References].," Aust. Psychol., vol. 50, no. 3, pp. 241-247, 2015.

[9] Muskin, Joshua A, and Ibe, "Continuous assessment for improved teaching and learning: a critical review to inform policy and practice; Current and critical issues in curriculum, learning and assessment; Vol.:13; 2017," no. 13, 2017.

[10] E. Kartikadarma, T. Listyorini, and R. Rahim, "An Android mobile RC4 simulation for education," World Trans. Eng. Technol. Educ., vol. 16, no. 1, pp. 75-79, 2018.

[11] C. Jones, "Assessment for Learning," Learn. Ski. Dev. Agency, pp. 16-19, 2005

[12] D. Camacho, Á. Ortigosa, and E. Pulido, "AI Techniques for Monitoring Student Learning Process,” 2008, pp. 149-172.

[13] P. Schwartz and G. Webb, Assessment: Case Studies, Experience and Practice From Higher Education. USA: Kogan Page, 2012.

[14] A. S. Ahmar and A. Rahman, "Development of teaching material using an Android," Glob. J. Eng. Educ., vol. 19, no. 1, 2017.

[15] N. Nasrudin, I. Agustina, A. Akrim, A. S. Ahmar, and R. Rahim, "Multimedia educational game approach for psychological conditional," Int. J. Eng. Technol., vol. 7, no. 2.9, pp. 78-81, 2018.

[16] K. Cotton, "Monitoring Student Learning in the Classroom," Sch. mprovement Res. Ser., 1998.

[17] N. Arsyad, A. Rahman, and A. S. Ahmar, "Developing a selflearning model based on open-ended questions to increase the students' creativity in calculus," Glob. J. Eng. Educ., vol. 19, no. 2, pp. 143-147, 2017.

[18] Abdul Rahman and Ansari S. Ahmar, "Relationship between learning styles and learning achievement in mathematics based on genders," World Trans. Eng. Technol. Educ., vol. 15, no. 1, pp. 7477, 2017.

[19] C. Caballero and A. Walker, "Work readiness in graduate recruitment and selection: A review of current assessment methods," J. Teach. Learn. Grad. Employab., vol. 1, no. 1, pp. 1325, 2010.

[20] K. B. Quansah, “Continuous assessment handbook,” pp. 1-36, 2005.

[21] T. van Gog, F. Paas, and J. J. G. van Merriënboer, "Effects of studying sequences of process-oriented and product-oriented worked examples on troubleshooting transfer efficiency," Learn. Instr., vol. 18, no. 3, pp. 211-222, 2008.

[22] H. Nurdiyanto, "A work-based learning model with technopreneurship," Glob. J. Eng. Educ., vol. 20, no. 1, pp. 75-78, 2018.

[23] D. Napitupulu et al., "Analysis of Student Satisfaction Toward Quality of Service Facility," J. Phys. Conf. Ser., vol. 954, no. 1, 2018. 